\title{
Memoria al servicio de la transformación
}

\section{Introducción}

La UCA ha celebrado el XXV aniversario del martirio de las dos colaboradoras y los seis jesuitas entregados al servicio de construir paz con justicia. Esta conmemoración, además, se celebró como inicio de otra serie de recuerdos y acontecimientos que también implican fechas con números redondos. El asesinato de monseñor Romero cumplirá 35 años en pocos meses y la propia UCA celebrará sus 50 años de existencia entre estos aniversarios martiriales y los del año próximo. Se abre así un tiempo de recuerdo de fuerte significatividad, de reflexión y de revitalización de decisiones y opciones que sigan encaminando la construcción de nuestra historia universitaria hacia horizontes de convivencia fraterna. Si usamos la distinción de Tzvetan Todorov entre memoria literal y memoria ejemplar, no hay duda de que la ejemplaridad de los acontecimientos que recordamos nos impulsa siempre, desde su profunda significación, a revisar la historia actual, a criticarla y a poner los medios, usando el vocabulario de Ellacuría, para revertirla y ponerla al servicio de lo humano. La memoria, cuando se fija en lo inhumano, descubre siempre la necesidad de recalcar y reclamar las dimensiones de la dignidad humana que las leyes de amnistía o de perdón y olvido tratan de sepultar. Intentar privarnos de la memoria equivale a tratar de impedirnos pensar. El recuerdo de los mártires nos despierta siempre de las ensoñaciones y propagandas del presente y nos impulsan a mirar la realidad libre y críticamente. La memoria es, en ese sentido, una verdadera victoria de lo humano: victoria contra el poder de la fuerza bruta, contra la muerte y contra la nada. Y clamor permanente de verdad, de justicia, y fin de la impunidad y del abuso sobre los débiles.

\section{Víctimas con significado}

Entre la historia del pueblo salvadoreño y la historia de la UCA, anterior y posterior al martirio que celebramos, hay una clara identificación. Las ansias de justicia, la búsqueda de caminos de convivencia pacífica, la indignación y crítica frente a toda explotación, la elaboración de ideas que marquen rumbos hacia la democracia y el bienestar compartido, el acompañamiento de las víctimas de ayer y de hoy son al mismo tiempo historias y necesidades de nuestro pueblo, y vivencias y opciones de la UCA. La misma fuerza en el caminar y la reivindicación, la misma sangre derramada, la misma búsqueda de reparación y el mismo sueño de un futuro más justo unían y unen al pueblo salvadoreño y a la UCA. No es raro que en esas circunstancias se produzca en nuestros aniversarios, y en este último en especial, lo que el Papa Francisco llama "el gusto espiritual de ser pueblo". La UCA no se considera a sí misma un coto cerrado, ni un refugio ante las dificultades, 
sino un lugar en el que se camina con las mismas esperanzas y dolores, alegrías y angustias del propio pueblo salvadoreño. Fue así en las propuestas de Ellacuría y sus compañeros, empeñados en impulsar una nueva civilización en la que los pobres tuvieran voz eficaz y transformadora. Siguió siendo así en el derramamiento de sangre de 1989. Y así ha permanecido la UCA acompañando la historia del pueblo mientras las élites prostituían la justicia con el perdón y olvido, intentaban despojar una vez más a los pobres de su dignidad y fomentaban desde un neoliberalismo salvaje la ola de violencia que nos ha caracterizado desde prácticamente el fin de la guerra civil.

Y por eso mismo, este aniversario se ha convertido, una vez más, en un ejercicio de significación de las víctimas. Los vencedores, los que al final de una guerra resultan beneficiados, tratan siempre de suprimir la significatividad de las víctimas. Sin embargo, el dolor de las víctimas continúa siempre en la memoria de quienes sufrieron su pérdida. Y al recordarlas, al explicitarlas y hacerlas presentes una vez más se les da significado. El recuerdo despierta tanto deseos de justicia e indignación, ante la perpetuación de las pautas de brutalidad que siguen causando dolor y muerte, como solidaridad con quienes continúan sufriendo patrones de comportamiento inhumano o simplemente son víctimas de estructuras sociales que producen exclusión, deterioro simbólico de la propia dignidad y marginación social. Las víctimas universitarias, que pusieran su racionalidad, discurso y capacidad de investigación al servicio de las causas de los pobres, potencian en ese sentido el análisis de las miserias del presente, refuerzan la capacidad crítica y muestran un camino de acompañamiento radical de toda aquella persona o colectivo cuya dignidad humana se vea recortada, golpeada o destruida. Mientras el victimario busca refugiarse en la mentira, en el dinero que paga manipulaciones u ocultación de los hechos y en la impunidad legal, la verdad débil y desnuda de las víctimas se abre paso desde su propia fuerza enraizada en la generosidad inocultable, en la inocente claridad de su vida y en los visibles ideales de servicio.

Su mensaje, tan profundamente En realidad, y desde nuestra propia visión criscristiano como humano, tenía una tiana, renuevan, crean y abren, en continuación con indiscutible repercusión política una nueva y vieja tradición eclesial al mismo tiempo, en El Salvador.

el camino de lo que podríamos llamar martirio político. No porque tuvieran una opción política partidista, sino porque su mensaje, tan profundamente cristiano como humano, tenía una indiscutible repercusión política en El Salvador. Renuevan porque ya monseñor Romero había sido un auténtico mártir con clara incidencia en la política de El Salvador. Crean porque le añaden al martirio de monseñor Romero la dimensión del intelectual universitario comprometido. Y abren la puerta, junto con monseñor Romero, para reconocer que este tipo de martirio tiene sus más íntimas raíces en las persecuciones que crearon el término "mártir", aplicado a quienes dan la vida y derraman su sangre al ser perseguidos por una causa. En efecto, el término "mártir", con el significado actual que le damos, fue creado, hacia mediados del siglo II de nuestra era, por los cristianos víctimas de la persecución del imperio romano. Y en esas persecuciones, pesó considerablemente la di- 
mensión política, entre otras dimensiones. El imperio romano, permisivo $y$, en general, complaciente con la pluralidad de las religiones, difícilmente soportaba que se le negara la dimensión divina al emperador, considerado en la tierra el representante de los dioses (o de la divinidad solar en algunos momentos) para dirigir la historia humana. Contrariamente, los cristianos pensaban que el único señor de la historia era el resucitado, Jesús, el Señor. Recuperar esa dimensión de incidencia en la historia en favor de la fraternidad humana frente a las idolatrías del dinero, del poder o de las conveniencias de grupo es, probablemente, la mejor herencia de los mártires políticos. Sepultar el recuerdo en el ámbito de lo privado sería conformarse con lo que llamaríamos una memoria ineficaz, que deja al margen la incidencia en lo público que tuvo ese tipo de muertes. Y las Iglesias que sean incapaces de reconocer la dimensión pública y política de sus mártires están abocadas a ir perdiendo significatividad en el mundo en que vivimos.

\section{En celebración de la dignidad humana}

Pero las víctimas despiertan también sentido de celebración. Son dignas, más dignas que los victimarios. Y el viejo deseo de la humanidad de que el verdugo no prevalezca sobre la víctima estalla en celebración cuando la dignidad del caído se eleva frente al desprestigio del agresor. Es evidente que la cúpula del ejército salvadoreño, en aquellos días de ofensiva general del FMLN, pensó que había llegado la ocasión propicia para descabezar al grupo de intelectuales que con mayor lucidez abogaban por la paz dialogada y la justicia social en El Salvador. No se detuvieron a pensar en la motivación que impulsaba el actuar de los jesuitas ni en la perseverancia que puede tener una institución religiosa en establecer verdad respecto a las situaciones límite en las que se ven envueltos sus miembros. Tampoco pensaron en la profunda fe religiosa del pueblo salvadoreño y creyeron que podían engañar, manipular, culpar a otros $y$, de paso, liberarse de uno de los sectores más críticos respecto a las violaciones de derechos humanos. Los jesuitas estorbaban a quienes buscaban desde todos los ángulos el triunfo militar y el dominio de la fuerza bruta, que incluye también la dictadura económica de los ricos. La defensa universitaria de los pobres, el pacifismo con justicia social y la búsqueda de una nueva civilización en la que los crucificados de la historia tuvieran plena dignidad se consideraba políticamente peligrosa y económicamente perjudicial para los intereses dominantes. Su apuesta por los derechos humanos y la defensa de estos llenaba de vergüenza a una Fuerza Armada demasiado salpicada de sangre inocente. Su pensamiento religioso, enraizado en la dimensión liberadora del Evangelio de Jesucristo, molestaba enormemente, en parte porque superaba los márgenes de las ideologías, siempre manipulables y sujetas a negociación, y entraba en contacto con los sentimientos más profundos del pueblo salvadoreño, cuestionando la ley del más fuerte e insistiendo en que el "pueblo deje oír su voz". Y fue precisamente este conjunto de elementos el que simultáneamente provocó los planes asesinos y generó la fuerza del reconocimiento popular 
de los mártires. Algo, esto último, que no tuvo en cuenta la "inteligencia militar" cuando diseñó los planes de muerte y encubrimiento. Convirtieron a los jesuitas en mártires no solo de la dimensión humana, sino del cristianismo profundo de nuestro pueblo. Por eso, incluso más allá de la verdad, que se ha ido abriendo paso sin que las instituciones militares o judiciales la reconozcan, la celebración será siempre una fiesta de

Solo el diálogo, la conversión a la fraternidad, el escuchar el clamor de los pobres conduce a soluciones verdaderamente pacíficas y auténticamente democráticas. la verdad, de la dignidad y del servicio de hombres y mujeres que desde su fe se unieron a la pasión y resurrección del pueblo salvadoreño.

En estos tiempos en los que crece el sentimiento de que se acerca el momento de la beatificación de monseñor Romero, se puede observar un claro paralelismo entre los mártires de la UCA y la figura señera de nuestro arzobispo mártir, que añade alegría y esperanza a la celebración de estos aniversarios. Frente a un concepto de humanidad construido sobre la apariencia y el prestigio prefabricado, frente a aquellos que ensalzan la fuerza militar, la abundancia económica, la permanencia en el poder, los mártires abren un nuevo camino de liderazgo salvadoreño. Se trata del liderazgo del servicio, de la opción por los pobres, de la construcción de la paz sobre la justicia, de la entrega de la vida en defensa de quienes no tienen voz, un liderazgo explícitamente cristiano que enlaza con los sentimientos más profundos de generosidad, de resistencia y de esperanza de nuestro pueblo. Por lo tanto, la celebración no es algo promovido desde fuera, sino que surge de lo más profundo de la conciencia de la gente.

Cuando la UCA le dio el doctorado honoris causa en Teología a moseñor Urioste, este antiguo vicario general de tres arzobispos insignes comentaba que, si la guerra civil había iniciado después de la muerte de monseñor Romero, el horizonte y la cercanía de la paz comenzó a brillar con luz más intensa tras la muerte de los jesuitas. Si con la muerte del arzobispo mucha gente abandonó la esperanza de una solución pacífica al conflicto social y político existente, la muerte de los jesuitas volvió a poner en el tablero de la conciencia lo que siempre dijo monseñor Romero: que la muerte violenta no es solución para los problemas humanos; que solo el diálogo, la conversión a la fraternidad, el escuchar el clamor de los pobres conduce a soluciones verdaderamente pacíficas y auténticamente democráticas. Despertar de nuevo el pacifismo de monseñor Romero y colocarlo en los corazones de los salvadoreños fue sin duda un trabajo colectivo en el que figuraron personas insignes, de las que solo nombraremos a monseñor Rivera y a María Julia Hernández, junto con los jesuitas asesinados, los cuales, desde un primer momento, con muchos otros y otras, trataron de hacer presente en nuestra historia al arzobispo mártir como un estímulo para la paz y la reconciliación. En ese sentido, no se puede celebrar a los jesuitas y sus colaboradoras separándolos de monseñor Romero. Sus publicaciones sistemáticas sobre el pastor asesinado, la continua difusión de su figura, el cariño y la devoción, la seguridad de que con él "Dios había pasado por El Salvador", los une a esa 
dimensión martirial y a esa historia de servicio que nuestro pueblo celebra año con año.

\section{Un pasado con protagonismo de futuro}

No se puede hablar de celebración sin mencionar de alguna manera el dinamismo de resurrección del mártir. A monseñor Romero se le atribuye una fase ya famosa entre quienes lo recordamos, que reza así: "Si me matan, resucitaré en el pueblo salvadoreño". No es una frase pretenciosa. Es la convicción que expresa una persona que ha puesto su vida al servicio de la dignidad de las víctimas empobrecidas y sin voz. Expresa la seguridad del que cree en la vieja frase que repitieron los mártires de antaño, insistiendo en que la sangre derramada es verdaderamente una semilla. Y es también el sentimiento y la realidad que provocan los mártires de la UCA. Porque en efecto, tanto Romero como los jesuitas y sus colaboradoras se unieron - primero, con la palabra y, luego, con la vida- a la suerte de tantas víctimas inocentes de una guerra de poderosos contra débiles, de ricos contra pobres. La carta de monseñor Romero al presidente, coronel Molina, denunciando la masacre de las Tres Calles ya en 1975 se convirtió muy pronto en profecía de la brutalidad que se estaba incubando en el país. La lista de asesinatos, con la muerte de Rutilio Grande incluida, inflamaba el corazón con profecía. No en vano el arzobispo de San Salvador ha iniciado la causa de beatificación de este primer jesuita asesinado. Los jesuitas de la UCA le sobrevivieron un tiempo y se convirtieron también en testigos de otras muertes, tanto más terribles cuanto más indefensas: los rostros de los niños de El Mozote, de los ancianos del Sumpul, de las mujeres de Las Hojas, de los ametrallados y ahogados al huir de Copapayo y de tantos otros, hombres y mujeres pacíficos y víctimas indefensas, convirtieron a profetas $e$ intelectuales en mártires políticos. Los conmovieron y movieron desde su dolor y los animaron y motivaron a arriesgarse incluso hasta derramar su sangre por restaurar una relación humana y no criminal en la "polis", en la convivencia ciudadana.

Las víctimas se convierten así, a través de los profetas, en protagonistas de la historia. En personas que claman por la justicia y por la paz desde la voz de quienes se comprometen con la historia de los pobres y con la búsqueda, junto con ellos, de una nueva civilización y cultura. No es en vano que, en el año 2010, la Asamblea General de las Naciones Unidas proclamó el 24 de marzo como "Día Internacional del Derecho a la Verdad en relación con Violaciones Graves de los Derechos Humanos y de la Dignidad de las Víctimas". El pasado de quienes dieron la vida sigue trabajando en el futuro y en la historia con una plenitud mayor. Acompañados por las víctimas de la historia, víctimas ellos mismos, se convierten en una especie de marea de humanidad que humaniza la historia y la relanza hacia la fraternidad y la verdad. Las celebraciones de la UCA se unen así a ese profundo latir de un mundo que anhela paz con justicia. Se honra el pasado porque tiene dimensión de futuro y porque se convierte ya, en el presente, en la manera más digna y humana de impedir que la muerte triunfe sobre la vida. La memoria, la celebración de la misma y el ímpetu que imprime hacia la cons- 
trucción de un futuro más humano, logra revertir la condena a la nada que los poderosos y prepotentes habían lanzado hacia los débiles y desposeídos de la historia. Los que en un momento fueron constituidos malditos por quienes se creían señores de la historia regresan en la memoria con un nuevo señorío, habitan en nosotros y nos impulsan desear y construir un mundo más humano. Son historia fecunda que inspira y relanza hacia el futuro. Los desafíos del presente, tan numerosos y complejos, pierden su tonalidad de empresa imposible al ponerse los hombres y las mujeres del presente en unión íntima y festiva con los rebeldes en Cristo que, al lado de los pobres y las víctimas, nos mostraron el camino de la dignidad humana. 